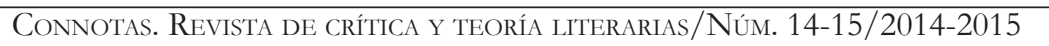

\title{
Espacio, lenguaje e identidad en Estrella de la calle sexta de Luis Humberto Crosthwaite
}

\author{
José Miguel Candelario Martínez*
}

Resumen:

La llamada literatura del norte exige una teorización en torno al espacio en el cual cobra gran trascendencia la cercanía de los Estados Unidos y, por lo tanto, las imágenes que se producen en torno de la frontera y su particularidad. Lo anterior da como resultado una gran cantidad de variantes ideológicas y lingüísticas, que en la obra de Luis Humberto Crosthwaite aparecen en la configuración del habla popular de sus personajes y su caracterización, quienes presentan sus conflictos en una Tijuana extravagante y poética, en la cual tiene lugar el choque de rasgos culturales entre la lengua inglesa y la española. Por lo tanto, en este artículo se analizan las afinidades temáticas y formales entre un conjunto de cuentos de este escritor, unidos por ese interés en un espacio fronterizo como escenario de tránsito y encuentro. El autor de "Sabaditos por la noche" lleva a cabo una recreación poética, no mimética, de los límites nacionales, algo que resulta clave para la comprensión de su propuesta artística. La frontera, en Crosthwaite, no es así entendida como un mero escenario, sino como un elemento clave en la construcción del relato y su apelación a ciertos significados. Estamos ante la tematización del espacio y la unión de elementos universales y regionales que se creen mutuamente excluyentes.

\section{Palabras clave:}

Frontera, literatura del norte, habla popular.

* Universidad Autónoma del Estado de México. 
Hablar de literatura del norte de México exige, desde su clasificación, un posicionamiento espacial que involucra, como es sabido, variantes ideológicas, lingüísticas y formales que dotan de una personalidad única a los textos producidos en estas ciudades tan diversas entre sí, pero al mismo tiempo con características muy semejantes. La distancia respecto al centro político y cultural así como la cercanía con el país vecino han generado, a través de los años, un cariz especial en los grupos sociales que habitan este territorio y, como es lógico, en sus producciones artísticas. Esta conciencia sobre el espacio que habitan y sobre sus diferencias respecto al resto del país, y respecto al vecino del norte, ha hecho del espacio un tema fundamental para la literatura fronteriza, una preocupación constante que los escritores buscan reproducir y, de algún modo, resolver en sus textos creativos. Tal es el caso del narrador tijuanense Luis Humberto Crosthwaite, quien sitúa sus historias en una Tijuana que se presenta extravagante y poética, por ser el punto de encuentro de grupos sociales diferenciados lo mismo que de lenguas igualmente distintas; esto es, el inglés y el español.

La literatura de frontera hace referencia a un espacio que se remite, fundamentalmente, al lugar de su producción y de su publicación, así como al tema o ambiente de sus historias. El espacio puede estar tematizado en un texto sin necesidad de manifestarse formalmente en la estructura de la obra; no obstante, una pieza narrativa que busque hablar de un lugar relevante para la trama, así como de sus problemas y circunstancias, tratará de reproducirlo no solo temáticamente, sino como un mecanismo fundamental del funcionamiento de la obra a la vez que como un elemento clave de la construcción, poniendo a trabajar en comunión el fondo y la forma para que, de este modo, se destaque la preeminencia que tiene como tema y como instrumento de la construcción.

Para analizar este aspecto de la narrativa de Crosthwaite tomaré como objeto de estudio el relato "Sabaditos por la noche", incluido en el libro Estrella de la calle sexta (2000), que contiene además dos textos más o menos extensos, que son "Todos los barcos" y "El gran preténder". Éste último, reeditado para el volumen, puesto que apareció por primera vez como libro independiente en 1992. Si 
bien los relatos pueden parecer disímiles entre sí, hay entre ellos afinidades temáticas y formales que tienen como eje director el tema del espacio; sobre todo, ese espacio característico que es la frontera y todo lo que conlleva como territorio de tránsito y encuentro. Por esta razón, las acciones de los personajes sobre planos problemáticos que determinan su vida y sus historias. En palabras de Rodríguez Lozano:

Desde su primer libro y hasta el último, la presencia de la frontera, concretamente el espacio de la ciudad de Tijuana, forma parte de los personajes y las situaciones que se cuentan en las diferentes historias, ya sea por medio del cuento, la novela o el testimonio. No se trata, por supuesto, de una visión lineal, turística, teórica, institucional o posmoderna, por el contrario, es la puesta en práctica de un discurso que revitaliza la dinámica de tal lugar(35).

Es ese lugar, que la narrativa de Crosthwaite recrea poéticamente, y no de manera mimética, lo que interesa para este trabajo, ya que reproduce en el universo del texto un mundo autosuficiente muy parecido a aquel que lo motiva y le sirve de fundamento. Humberto Félix Berumen, a propósito de ese asunto señala:

Hablamos de una frontera textual, es decir de la frontera asumida como espacio narrativo; incluso podríamos hablar de un cronotopo literario, del cronotopo de la frontera; es decir, de la reconfiguración de la frontera desde la ficción narrativa como espacio imaginario. La frontera deja de ser una referencia geográfica para convertirse en una realidad imaginada, sentida y valorada por aquellos que la han asumido como parte de sus respectivos relatos (125-26).

El cronotopo de la frontera es importante en cuanto que sirve de marco o ambiente para las historias, pero es igualmente relevante, y eso es precisamente el tema de este trabajo, la forma en que el espacio de la narración, inspirado en el territorio fronterizo, sirve como elemento constructor del relato y como una más de las partes 
del sistema total que es la obra narrativa. Ambos sin duda emparentados, pero con funciones distintas, ya que pertenecen a distintas categorías; uno es el marco referencial, que pretende reproducir la realidad social y geopolítica y, otro, un mecanismo estructural que cumple una función específica en el organismo del texto.

El título que agrupa los relatos, Estrella de la calle sexta, pone a dialogar dos elementos de distinta índole y de campos semánticos diferenciados, "estrella" y "calle" (lo alto y lo bajo, lo elevado y lo mundano), que revelan una clave para la comprensión de los textos, ya que estos pondrán a funcionar problemas humanos de gran importancia, asociados con lo sublime como el amor, la soledad, el ser, en un contexto de congales, borrachos, alcohol y prostitutas, en un ejercicio que combina y hace convivir lo universal con lo transitorio, lo noble con lo rastrero. Todo esto no de manera antagónica, como la puesta en escena de un combate entre enemigos irreconciliables, sino como la fusión de elementos que se creerían incompatibles, pero que, al fusionarse, dotan de un matiz distinto al espacio tematizado, dándole una profundidad y un valor poético que lo rescatan y que desdibujan, por momentos, esa fachada de ruina y descomposición moral que se le ha atribuido, desde siempre, a las ciudades de la frontera norte de México.

En "Sabaditos por la noche", el personaje narrador es el testigo a través del cual se percibe el mundo del relato; sus ojos y oídos darán cuenta del universo que habita y su perspectiva respecto a este ayudará a definirlo emocional y ontológicamente. El personaje, gringo de ascendencia mexicana, que habita en los "únaired" (United Sates), ingresa cada sábado a un lugar de México, que puede asociarse con Tijuana, la tierra del autor, y reclama para sí un territorio que, él asegura, le pertenece. Este posicionamiento lo sitúa como eje y centro de un espacio que despliega a su alrededor y que, mediante su testimonio, el lector conoce. Su reclamo de pertenencia al mundo de "este lado" es también la búsqueda de una parte de su identidad que los demás personajes no le atribuyen (por considerarlo un "gringo"; es decir, lo otro), pero que él sabe perfectamente que posee.

El texto comienza con el deíctico "aquî", que indica el lugar del narrador y con el verbo "mirar" que remite a su actividad: "Hey, 
hey, aquí nomás mirando pasar las beibis. Todos los sábados me encuentras sentadito en esta esquina, tripeando, agarrando mi cura. ¿Ya viste aquella morra? Por eso estoy aquí, mirando mirando" (Crosthwaite 13). Así pues, el personaje ofrece un par de claves sobre los aspectos fundamentales de su personalidad estableciendo un posicionamiento que le permite tener el mundo frente a él para así observarlo. No es para nada gratuito, además, que en las primeras líneas aparezca mencionada la mujer (la morra) como la causa por la cual el narrador se sitúa en la esquina-centro; la función que las mujeres desempeñan en el relato es crucial, dado que ellas suelen ser el móvil de las acciones, lo mismo que los interlocutores que posibilitan el discurso del protagonista, quien ante ellas se permite una emotividad mayor. Por si fuera poco, la interrogación dirigida a un "alguien", que se relaciona directamente con el lector, propone la interlocución entre narrador y lector que da un carácter de testimonio a lo contado por el primero. Dice enseguida:

Yo no soy como cualquier imbécil que se la pasa guachando a las beibis, nel, soy un imbécil especial, al tiro. ¿Me entiendes? Ya recorrí el mundo, ya nadie me cuenta lo que es bueno y lo que es malo. Yo escogí los caminos y escogí también que mis sábados pasen en esta esquina (13).

Con el uso de la interrogación "¿me entiendes?" el narrador busca conectarse con un interlocutor y trata de mantener, mediante la función fática del lenguaje, como en una conversación no mediada por la escritura, la atención de otro, cuya comprensión procura. El lector, a su vez, tendrá que reconstruir con sus propios materiales, y con lo referido por el narrador, su propia imagen de la ciudad. En palabras de Quackenbush: "Las obras de Crosthwaite dependen de la autoidentificación de su público con el tercer país que inventa en su prosa ${ }^{1}$. Cada lector actualiza este mundo según su

\footnotetext{
${ }^{1}$ Conviene señalar, en este punto, la relación que puede establecerse entre las ideas de Quackenbush y las expresadas por Homi K. Bhabha. Este último
} 
conocimiento y sus limitaciones lingüísticas, históricas y culturales" (152). Este tercer país alude a la confluencia de grupos sociales y lenguas distintas que genera una tercera instancia que es distinta, pero que se nutre de las anteriores. Por ello, el personaje se ve obligado a insistir en la descripción del espacio, pues sabe que lo que trata de referir se encuentra poblado por lo abigarrado y lo diverso, de modo que procura transmitir una imagen lo más fiel posible para no ser malinterpretado, porque esto involucra un juicio por parte del oyente o receptor, quien terminará asociándolo con un grupo social o con otro, ya sea con los mexicanos o con los gringos. El narrador-protagonista regresa a este país a buscarse, porque no se encuentra a sí mismo entre los anglosajones que, seguramente, lo marginan, pero, tristemente, no tiene una recepción distinta entre los hispanos.

El uso reiterado de las expresiones "mi esquina" o "esta esquina" da al espacio un valor significativo a la vez que refiere la fijeza de su habitante, quien parece detenido perpetuamente en ese lugar, lo que reproduce una imagen algo estatuaria. Esta fijeza habla de pertenencia y de imposibilidad de salida. El personaje vuelve a este lugar periódicamente como se vuelve al origen, a su identidad. Recordaré en este punto lo señalado por Paz respecto al sentido de soledad del mexicano:

El sentimiento de soledad, nostalgia de un cuerpo del que fuimos arrancados, es nostalgia de espacio. Según la concepción muy antigua y que se encuentra en casi todos los pueblos, ese espacio no es otro que el centro del mundo, el "ombligo" del universo (356)

Así pues, el protagonista de este relato reconoce que no pertenece al mundo del "gringo", sino al de este lado de la frontera, el de

sitúa en ese punto de enfrentamiento de dos culturas diametralmente opuestas un "tercer espacio", surgido de la necesidad de llevar a cabo una "traducción cultural" que medie entre ambos esquemas epistémicos. 
su origen, por lo que su vínculo con la madre es mayor que con el padre, quien desde el inicio se muestra ausente del núcleo familiar: "¿Quién falta en esta familia feliz? Adivina, ándale. Los hombres, los batos, los rucos. ¿Dónde estoy, dónde está mi padre?” (Crosthwaite 41). Así pues, la actitud de objeto inamovible es análoga a la del árbol de raíces profundas que es parte del paisaje, tal como es presentado el narrador del relato. Sus raíces y su vuelta a esta tierra hablan de su identificación con el grupo social y con la lengua de la madre, a quien asocia con los personajes que habitan esta zona:

- ¿Ve aquella señora, ¿la mira allá en el fondo?

$-¿$ Qué tiene, mijo?

-Se parece a mí mamá, que en paz descanse.

-Ya me lo dijiste, mijo, ¿no te acuerdas? La semana pasada (30).

Las figuras del padre y de la madre están igualmente ausentes en la vida del protagonista; sin embargo, solo siente empatía por la madre; el padre es un gringo, un otro, un extraño con el cual no se identifica y al cual observa con distancia crítica. Por tal motivo, las similitudes que puede haber entre ambos son rechazadas tajantemente:

Sí, tuve un padre y él sí tuvo un hijo. Guacha: te lo puedo dibujar. ¿Ah, no? Pues aunque no quieras, imagínate la foto. Six-fut-faiv. Grandote, el condenado. Güero güero güerísimo con pelo lacio color dorado como las pinturitas de aceite marca Testone. Ah, ¿se parece a mí? Ni de chiste (42).

El gringo, para el protagonista narrador, representa al extranjero, al otro que no comprende su situación y que no alcanza a penetrar en su pequeño espacio, ese espacio que se ha encargado de delimitar y de cerrar a los demás, salvo algunas excepciones como Laurita o ese otro que escucha su relato y lee su historia en el texto. Su reclamo del espacio, entonces, está justificado. Nadie le atribuye una similitud con la cultura mexicana y, por ello, es él quien tiene que hacer notar que el territorio le pertenece, que sus raíces también están clavadas en la tierra de este lado de la frontera. 
Situado en la calle sexta, el protagonista se vuelve la "estrella" de este espacio; es decir, el protagonista del relato, pero a su vez el testigo que ve, como desde arriba, lo que acontece en la tierra. Además, siguiendo a Cirlot en su explicación sobre la simbología de la estrella, se podrá interpretar que en este personaje existe el reclamo de un centro: "La 'identificación con la estrella' representa una posibilidad sólo reservada al elegido ... La estrella llameante es un símbolo del centro, de la fuerza del universo en expansión" (204). De este modo, su conciencia de ser el centro, de estar en el centro de ese mundo, destaca la importancia del lugar, a la vez que le otorga rasgos de universalidad, puesto que no se trata ya del margen o de la excepción, sino de los problemas fundamentales del ser humano.

Pero podría interpretarse también, ignorando el carácter de dandy seductor que caracteriza al protagonista e ignorando su calidad de eje del espacio, que la estrella de esta calle es Laurita, la prostituta novia de Ciruelo, de quien el narrador parece estar enamorado. ${ }^{2}$ La mirada, entonces, pasaría de testigo dominante de un territorio a testigo deseante que se sitúa en un nivel inferior. Desde abajo, el protagonista ve a la mujer como inalcanzable y, a pesar de esto, cifra en ella sus esperanzas y su posibilidad de salida. En el texto:

Cuando decido entrar en el bar me gusta que ella sirva las copas y como ya sé cuáles son sus mesas, pos por allí me siento y ella siempre está sonriente y yo nunca le he tirado la onda, de veras, no le he dicho cosas locas como a las otras beibis. La verdad es que Laurita la delgadita se lo merecería, para qué negarlo, con mucho gusto, casi como un deber, le mordería los huesitos y le chuparía el tuétano toda la noche. Pero no sé. La veo y no sé (Crosthwaite 17).

\footnotetext{
${ }^{2}$ Encuentro que el título que agrupa a los textos como conjunto más bien parece un título alternativo para el primer relato "Sabaditos por la noche", porque es en este donde más se insiste sobre la calle sexta.
} 
Como puede verse, el movimiento del personaje es voluntario. Es él quien decide trasladarse y llevar el escenario consigo; él decide, además, entrar en el bar en busca de Laurita, quien parece ser la única instancia receptiva en un mundo hermético y de rechazo mutuo. Al contrario de otros personajes que parecen invadirlo, el protagonista se siente bien recibido por el personaje femenino, con el cual habla y se comunica, cosa que no hace ni siquiera con el cantinero, ya que es este quien cuenta sus penas al protagonista invirtiendo el rito de confesión de las cantinas. De otros personajes, de aquellos que invaden su espacio el narrador protagonista ha dicho:

Yo sonrío, sin mirarlo, no quiero darle mucha confianza, no conviene si lo acabas de conocer. Mejor, si tiene algo que decirme que lo diga ya, que no se ande con rodeos, y nomás que no me salga con ondas extraterrestres, que no me lance rollos alienígenas porque no sé cómo voy a responder. Lo que pido es respeto (18).

El sujeto se refiere al tema de la homosexualidad, tema que igualmente localiza fuera de su espacio íntimo. Los "rollos alienígenas", "extraterrestres" hablan de algo que viene de fuera y que no es parte de ese territorio personal que el narrador se empeña en defender, porque el espacio y el individuo son uno solo; por ello, la irrupción del otro es vista de modo negativo. La desconfianza y la incomprensión suelen darse entre los personajes masculinos: "Laurita la delgadita no se ríe ni se burla de mí, tengo que aclararlo. Me refería a los batos; Laurita la delgadita no. Ella es una morra que no-tiene-mucho-que-decir, que no se mete con nadie" (17). Los hombres son extranjeros los unos para los otros, cada cual posee su espacio personal que defiende con un hermetismo que genera la incomprensión y son las mujeres, en este caso Laurita, quienes permiten la comunicación y la socialización. El otro llega con asuntos que provienen de otros planetas, es decir, de un territorio harto distinto al del personaje. Por eso reclama su espacio y exige respeto, no desea que nadie penetre en su interior, sus lentes oscuros son la frontera que impide ese paso, porque lo resguardan y ocultan. Para- 
dójicamente, con su interlocutor, el lector del texto, así como con la mujer, el narrador se permite estar descubierto como deseando ser observado y conocido:

¿Crees que te estoy cuenteando? Asómate a mis ojos, aguántame la mirada, ¿ves?, me quito los lentes oscuros, ¿ves? Soy un tipo duro como este piso, soy un tipo duro que se ablanda de vez en cuando con la sonrisa de Laurita que es suave y brillosa como el cofre de un carro recién pintado (17).

El personaje hace partícipe a su interlocutor de una afirmación identitaria, porque está en constante búsqueda de su propia definición como ser individual y social; él entiende que es el producto de dos culturas distintas que se fusionaron para darle origen y, por ello, busca defender la existencia de ese territorio de cruce que es la calle que visita, porque en esa calle ve cifrada su naturaleza. Su constante insistencia en los rasgos de su personalidad buscan dejar claros los componentes de su ser, que asocia con la gente y el territorio fronterizos. En palabras de Llarena: "Y es que el espacio de la percepción es siempre una configuración de la conciencia, el resultado de nuestra interacción con el medio, tamizada lógicamente por nuestras propias impresiones y vivencias, determinantes en el conjunto de nuestra sensación espacial" (94). De este modo, el espacio, solo conocido mediante la intervención del personaje y filtrado por este, provoca una simbiosis indisoluble con el protagonista volviéndose ambos una sola cosa. Cuando el narrador habla de la calle, habla también de él mismo y de su situación emocional, trasladando sus conflictos a su contexto, objetivándolos. No es una calle que ve desde fuera, no es un barrio de faro rojo cualquiera, que puede atestiguar como en laboratorio, en un ejercicio de naturalismo; es, más bien, el pretexto para hablar de sí mismo y de su miseria personal; la descripción del espacio es la descripción de su alma. Así se presenta en el texto:

Te voy a decir cómo es esta calle, cómo es mi esquina, cómo es la raza que pasa por aquí en la noches. Sí sí, se trata de mi interpretación personal, ya sé que tú también puedes verla. Ya 
sé, ya sé no me interrumpas... no tiene una iglesia o una cruz roja que la redima y la salve del infierno cuando se muera (Crosthwaite 21).

De esta manera, se incluye la reflexión sobre la subjetivación del espacio como una extensión del individuo, además se menciona otra carencia fundamental: la de la divinidad. El personaje atormentado por un pasado que desconocemos, por encontrarse apenas aludido por unas fotografías y unos pocos datos circunstanciales, oculta la verdadera tragedia. La iglesia y la cruz, totalmente ausentes en su vida, cancelan la posibilidad de salida y de redención. Quienes habitan esa calle, ese mundo, no tienen escapatoria, puesto que están condenados por sus pecados y esto porque el espacio ha calado hasta dentro de ellos, volviéndolos parte de su ser íntimo. Pero, como he expuesto aquí, el narrador no está hablando solamente del espacio, sino de sí mismo y esa condena que atribuye al lugar, más bien, es atribuible a su persona. Por ello, su relación con la mujer es igualmente irrealizable; no hay redención posible, pero no porque la zona no la tenga, sino porque él mismo no puede acceder a ella. Al descubrir que Laurita tiene una relación con el personaje llamado Ciruelo, al parecer proxeneta del burdel, el protagonista reflexiona:

¿De qué otra manera pudo haber sido? Laurita también es un sol, ¿por qué voy a pensar que sólo existe un mundo girando alrededor de ella?, ¿por qué no imaginar otras órbitas con otros planetas y otros satélites y las estrellas y meteoritos y asteroides y el pinche Ciruelo? (53).

De esta manera, el narrador abre la posibilidad de que así como él es el eje y centro del relato, del mismo modo, otros personajes lo son de su historia personal; sin embargo, ensimismado y retraído, no había percibido que esto fuera posible. Es en este momento, cuando descubre la realidad de los otros, que cae de su posición superior y descubre por fin la verdad. Los mitos de Ícaro y Faetón se repiten en esta obra. Tanto subió el protagonista y tan grandes fueron sus pretensiones que tuvo que adquirir el conocimiento de la peor manera: 
-Qué te pasa, güerito, no te andes cayendo.

La verdad es que no ando cayéndome, ya estoy caído. Y con mucha dificultad me levanto. Veo a Laurita saliendo del bar y logro sentarme de nuevo. El Ciruelo regresa a su mesa. Esta vez Alan Ladd estaba borracho. No cabe duda que los tiempos cambian.

-Creo que no te has dado cuenta - dice el Beto-, Laurita es la novia del Ciruelo. Al rato regresa, no es la primera vez que pasa (49).

La presentación del héroe cinematográfico, borracho e imposibilitado para alcanzar la justicia, contribuye a la imagen de los intentos heroicos que han sido frustrados por las propias imposibilidades y por la realidad que se opone al sujeto. Pero la caída no es el único mito puesto en juego. No es que el narrador protagonista no pueda concretar su encuentro con Laurita, pues eventualmente, cerca del final de la historia, lo consigue; sino que además, tiene que partir hacia el otro lado para volver la semana siguiente, lo que lo convierte en un Sísifo condenado a repetir una y otra vez la hazaña.

Lo que derriba al narrador es descubrir que no es él quien ordena las historias. Finalmente toma conciencia de que hay otras historias y hay otros ejes con otras órbitas y eso lo pone de vuelta en la tierra. Su intuición sobre esta realidad lo había llevado desde el principio a reclamar su espacio, lo que lo situaba como eje y centro, mientras que los demás constituían meros satélites de su persona. La dinámica del relato impedía que los demás personajes contaran su versión personal de los sucesos. Todos habían sido presentados por el personaje con vaguedad, sin precisar ninguno de sus rasgos, bastaba para calificarlos una palabra o un rasgo de físico o moral. Cuando la historia de Laurita irrumpe en el círculo del narrador este cae, porque ha descubierto que muchos otros tienen tragedias individuales semejantes a las suyas. Lo relevante aquí es que en ese lugar las historias pudieron encontrarse, aunque brevemente. El espacio principal reclamado con egoísmo por el narrador fue invadido por el otro, por la mujer; así como el territorio tematizado, el cronotopo de que se habló al principio, es constantemente penetrado por el 
otro que carga su historia personal. Con esta puesta en juego de distintos niveles en el relato el autor homologa elementos de distinta categoría: el espacio de la narración reproduce el espacio temático, la frontera; por tal motivo, quien defiende su identidad termina por descubrir que esta también se nutre de la presencia de los otros; todo esto no solo en un nivel sociocultural, sino íntimo-emocional. Uno existe porque tiene contacto con el otro, y este contacto también forma parte de su persona.

El personaje, señalé antes, no adquiere en la concreción de su encuentro con Laurita la satisfacción total. Es un ser deseante en perpetua búsqueda. Por eso tiene que salir de ese espacio, para volver a la otra mitad de su ser, a la parte complementaria de su identidad. Oscila entre aquel lado y este lado, vuelve cíclicamente, como en una espiral sin término, a este espacio para no quedarse. Su exigencia y su deseo de que el territorio fuera suyo estaban justificados, pero, eventualmente, el otro espacio lo atrae hacia sí. Huir de uno o de otro es imposible.

Lo mismo ocurre a nivel del lenguaje. El protagonista oscila entre dos lenguas que trata de reconciliar, incluso a ese nivel se nota la ambivalencia sociocultural que lo conforma. Hablando de su pasado, en conversación de borracho, señala:

Enseñándoles el faquin inglés porque se supone que sólo el faquin inglés pueden hablar en mi país de mierda, land-of-dafaquin-fri [land of the fucking free]. Nada de español, ¿ves?, nada que se le parezca. Por eso he decidido, damas y caballeros, que he hoy en adelante, mi lengua será el spánich, ¿qué te parece? El spánich and ay guont spik enithing els [spanish and I wont speak anything else] (41).

Puede verse, en la disposición gráfica de la pronunciación del inglés, una pugna igual a la espacial; incluso lo dicho en inglés quiere ser español, está escrito como si se tratara de español. Y, justo cuando ha decidido que su lengua será la hispana, su afirmación categórica es puesta en lengua inglesa como si, aún deseándolo, no pudiera escapar de ella. A propósito del lenguaje en el espacio, Foucault señala: 
Y si el espacio es en el lenguaje de hoy la más obsesiva de las metáforas, no es que ofrezca en adelante el único recurso; pero en el espacio es donde el lenguaje desde el principio se despliega, se desliza sobre sí mismo, determina sus elecciones, dibuja sus figuras y sus traslaciones. En él es donde se transporta -donde su ser mismo se "metaforiza" (196).

Estás ideas no se refieren al espacio geográfico o geopolítico, sino a la espacialidad del lenguaje, a sus posibilidades de disposición; pero es precisamente en este sentido en el que la reflexión del pensador francés es útil. El lenguaje es motivado o deformado por esos espacios dobles o antagónicos puestos en juego en el relato. Hay una coherencia con la doble identidad del individuo así como con una búsqueda personal de unidad. Pero tal unidad, siendo irrealizable, deforma igualmente el modo en que el individuo se expresa; por ello, su lengua oscila y busca un modo de expresarse que sea coherente con el hombre que enuncia, aunque claro, lo mismo se inclina para un lado que para el otro en una pugna irresoluble. Dice sobre esto Van de Wingard:

El hombre es un ser localizado. Su estado constitutivo es el aparecer arrojado sobre dos suelos primarios: la madre tierra y la lengua materna ... pertenencia doble: a tierra y lengua. Las dos conforman la duplicidad del territorio. Porque tierra es, también, una trama de significación, en equivalencia a la lengua (6).

El protagonista de este relato tiene la desventaja de no pertenecer a una lengua o a un territorio en específico; su configuración personal es doble y, por ello, su modo de expresarse lo es también.

Lenguaje, espacio y referencia social funcionan de modo similar en el relato de Crosthwaite; en ellos es visible una ambivalencia de identidades que expone una búsqueda de pertenencia y definición. El personaje, que une estas tres categorías con su historia personal y con su narración de los sucesos, sirve de eje para todos ellos, con la paradoja de que él mismo es un centro doble con una misión similar: la de reconciliar aspectos antagónicos y disímiles que le dan 
forma y que desea situar como problema fundamentalmente humano, no como problemática de política social. Ser doble también es ser, aunque eso no implique, necesariamente, pertenecer. Por ello el territorio es homologado a sus personajes, quienes han creado para sí ese espacio impreciso y diverso que es la frontera como un rasgo más de su esencia personal. Existiendo ese espacio, ellos pueden pertenecer y tener un lugar al cual acudir para refugiarse; un lugar al que pueden llamar propio.

\section{Obras consultadas}

Berumen, Humberto Félix. La frontera en el centro. Ensayos sobre literatura. Mexicali: Universidad Autónoma de Baja California, 2005.

Bhabha, Homi K. Nuevas minorías, nuevos derechos. Notas sobre cosmopolitismos vernáculos. Buenos Aires: Siglo XXI Editores, 2013.

Cirlot, Juan-Eduardo. Diccionario de símbolos. Colombia: Labor, 1995.

Crosthwaite, Luis Humberto. Estrella de la calle sexta. México: Tusquets Editores, 2000.

Van de Wyngard, Fernando. Citiedad. Santiago de Chile: El Aristotélico siniestro, 2000.

Foucault, Michel. De lenguaje y literatura. Barcelona: Paidós, 1996.

Llarena, Alicia. Espacio, identidady literatura hispanoamericana. México: Universidad Autónoma de Sinaloa, 2007.

Paz, Octavio. El laberinto de la soledad. Ed. Enrico Mario Santí. Madrid: Ediciones Cátedra, 2002.

Pavón, Alfredo, ed. Púshale un cuento al piano (la ficción en México). México: Universidad Autónoma de Tlaxcala; Instituto Nacional de Bellas Artes; CONACULTA, 2003.

Quackenbush, L. Howard. "La autoconciencia fronteriza y el tercer país en los cuentos de Luis Humberto Crosthwaite". Pavón 149-175.

Rodríguez Lozano, Miguel. El norte: una experiencia contemporánea en la narrativa mexicana. Monterrey: Consejo para la Cultura y las Artes de Nuevo León, 2002. 